\title{
The Carter Cuff: A Preliminary Assessment of Its Effectiveness in Enhancing Upper Body Strength in People with Unilateral Amputation and Other Disabilities
}

\author{
Marilyn Mitchell' ${ }^{1}$ David I. Anderson² \\ ${ }^{1}$ Department of Kinesiology San Francisco State University, San Francisco, CA, USA \\ ${ }^{2}$ Marian Wright Edelman Institute for the Study of Children, Youth, and Families, San Francisco State University, \\ San Francisco, CA, USA \\ Email: marilynm@sfsu.edu
}

How to cite this paper: Mitchell, M. and Anderson, D.I. (2017) The Carter Cuff: A Preliminary Assessment of Its Effectiveness in Enhancing Upper Body Strength in People with Unilateral Amputation and Other Disabilities. Open Journal of Therapy and Rehabilitation, 5, 118-138. https://doi.org/10.4236/ojtr.2017.54011

Received: August 24, 2017

Accepted: November 20, 2017

Published: November 23, 2017

Copyright $\odot 2017$ by authors and Scientific Research Publishing Inc. This work is licensed under the Creative Commons Attribution International License (CC BY 4.0).

http://creativecommons.org/licenses/by/4.0/

cC) (i) Open Access

\begin{abstract}
Five participants with unilateral, upper extremity amputation were recruited from a convenience sample and participated in a supervised resistance training exercise program in their own local exercise facility using the Carter Cuff (Carter Medical Devices, LLC). The Carter Cuff is a relatively new assistive device that allows people with unilateral, upper extremity amputation and other disabilities or injuries of the hand to engage in resistance training exercises. Following a six weeks training period, an online survey was made available to the participants who provided demographic information and answered questions about their exercise habits and their satisfaction with the ease of use and effectiveness of the Carter Cuff as well as its impact on their lives. The results of the survey provided preliminary support for the effectiveness of the Carter Cuff and its positive effects on people with amputations. Though more quantitative data on physiological and psychological measures are needed, these preliminary findings have important implications for occupational therapy practice.
\end{abstract}

\section{Keywords}

Amputation, Resistance Training, Assistive Device, Rehabilitation

\section{Introduction}

Resistance training exercise has been shown to have multiple positive effects on physiological and psychological function in adults with and without disabilities 
[1] [2]. In terms of the physiological benefits, it has been well-documented that resistance training exercise leads to increases in the size of the muscle, increases in short-term and long-term muscular strength, improvements in bone composition, reduction in resting heart rate and blood pressure, strengthening of cardiac tissue, favorable changes in blood lipids, and improvements in glucose metabolism [3]-[8]. These effects on physiological function have been shown to reduce factors associated with coronary heart disease, diabetes and osteoporosis. Positive psychological changes have also accompanied participation in resistance exercise training such as reduction in anxiety, depression, and chronic fatigue and improvements in self-esteem [9] [10]. As a result of this supportive research, the American College of Sports Medicine in 2011 published updated guidelines that included recommendations that resistance training exercise should be performed by all adults, including the elderly, at least two to three times a week [11].

Physical activity is seen as a crucial component of the rehabilitation process for people with disabilities [1] [2]. However, for people with upper extremity disabilities who find it difficult or impossible to use their hands, a reduction in the participation of resistance training exercise training and other forms of exercise is often observed [12]. The reduction of physical activity following hand injury or loss may result from a lack of assistive devices that enable the individual to continue to exercise.

To address these concerns, a new product has recently been developed by Carter Medical Devices, LLC, called the Carter Cuff (Figure 1(a) and Figure 1(b) about here). The Carter Cuff exercise device is an armband designed to be worn by a person who uses a prosthesis hand or a person with impaired hand function. The armband stabilizes the attachment of the prosthesis thereby allowing numerous pulling exercises that would otherwise be impossible and provides connection to exercise machines and free weights that would otherwise have to be grasped with the hand. The Carter Cuff is constructed from a sheet of flexible material that is sized to be wrapped around the wearer's arm, enclosing substantially all of the arm and the wrist or base portion of any prosthesis hand. The wrapped armband is tightened by attached cinching straps, and D-rings are attached to the surface of the armband for attachment to exercise machines or free weights. An optional shoulder harness can be attached to the armband for additional stability.

The purpose of the present investigation was to obtain qualitative data from a sample of people with unilateral, upper extremity amputation who were asked to use the Carter Cuff over the course of several weeks. With these data, we wished to determine whether the use of the Carter Cuff resulted in any positive physiological and psychological changes in the participants. Because the exercise period was only six weeks, we did not anticipate any significant observable physiological or morphological changes in the participants, but we were particularly interested in how the participants felt about the comfort of the Cuff and the feasibility and practicality of the Cuff as an assistive device for resistance training exercises. 


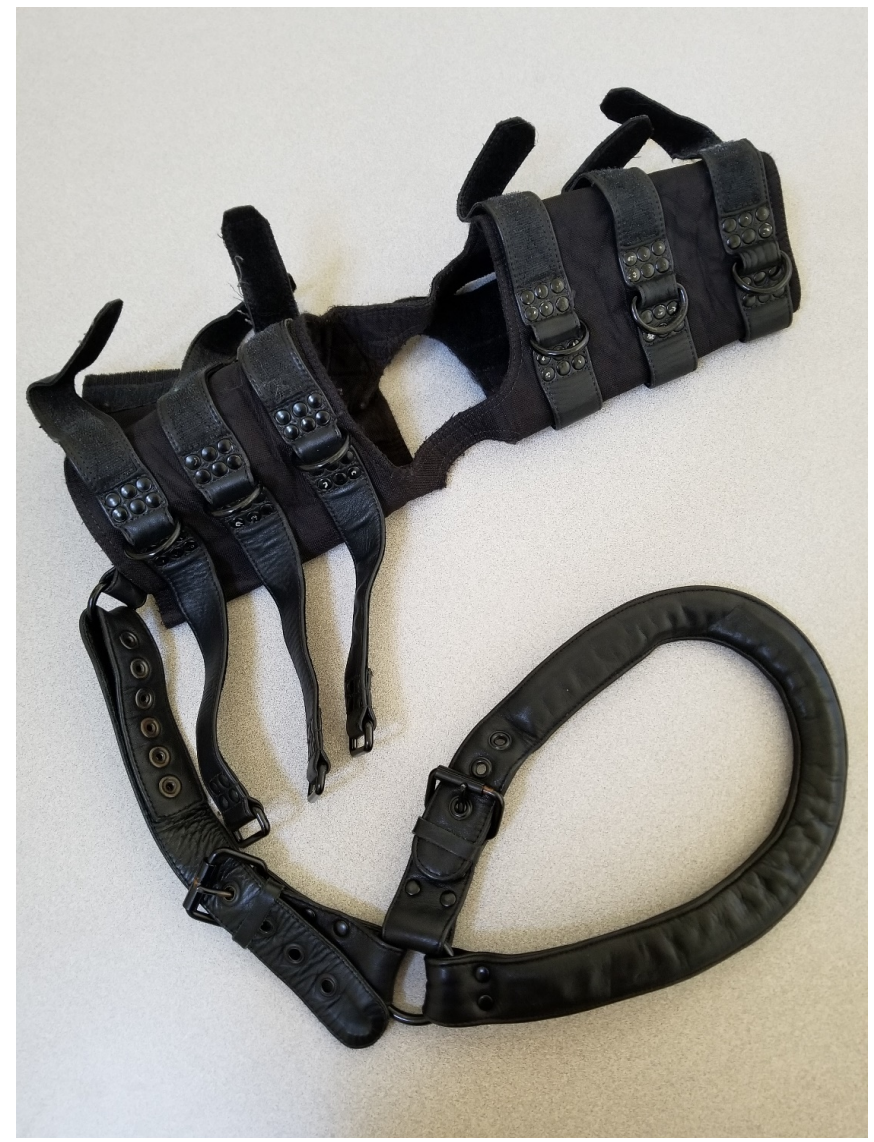

(a)

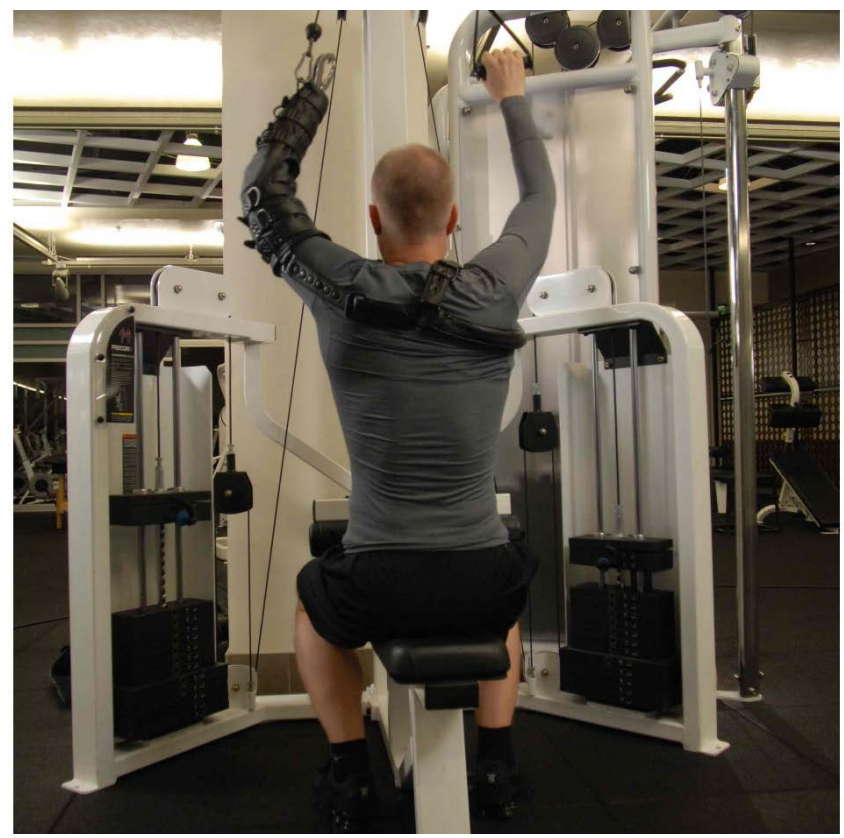

(b)

Figure 1. (a) The Carter Cuff. Notice the D-rings that allow for attachments to the exercise equipment. A shoulder strap that fits over the contralateral shoulder provides additional support for heavier loads; (b) A person with an amputation using the Carter Cuff over their prosthesis. Notice the $\mathrm{D}$-ring attachment to the exercise equipment. 


\section{Methods}

\subsection{Participants}

We were able to recruit participants by referrals from the CEO of Carter Medical Devices, Andrew Carter, who had various contacts with physical therapists or prosthetic providers. Our inclusion criteria were that: 1) participants had to have an unilateral, upper extremity, below elbow amputation; 2) some degree of experience using an upper extremity prosthesis; and 3) some experience with weight (resistive exercise) training. We examined user satisfaction of five people with unilateral upper extremity amputations that exercised with the Carter Cuff for a period of six weeks. All participants identified as white/Caucasian, but one as half Caucasian and half Asian. The age ranges for the five male participants were 18 - 25 (2), 36 - 45 (2), and 46 - 55 (1). Three of the participants had a left side amputation and the other two had a right side amputation. Three had trans radial amputations, while one had a partial hand amputation, and one a forequarter amputation. It had been at least 10 years since the amputation for all the participants. All participants had at least one year of weight training experience using a prosthetic device other than the Carter Cuff. Three of the participants had routinely worn a prosthesis and of these three, two used a myoelectric prosthesis while one wore a cosmetic prosthesis primarily. The present study was supported and approved by the institutional review board at San Francisco State University.

\subsection{Procedures}

A questionnaire consisting of questions (71) on demographics of the participants (1 - 31), user satisfaction and functionality for exercise type (32 - 48), user experience and effectiveness of weight training (49 - 64), and likes and dislikes (65 - 71) was provided to the participants via an online website. The questions are provided in Appendix. Following the six-week training period using the Carter Cuff, participants were asked to complete the questionnaire. Under supervision of their own personal trainer or occupational therapist, each participant exercised in a weight room within their own preferred, local exercise facility. The participants and supervisors were provided instructions on how the Carter Cuff was to be donned and doffed, and how it should attach to the exercise equipment, but they were free to determine, along with their supervisor, the frequen$c y$, duration and intensity of their workouts. The eight recommended exercises that were provided to the participants and their supervisors were: lat pulldowns, rows, triceps extension, chest press, fly, reverse fly, overhead press and biceps curl. These are very common resistive type exercises that have been thoroughly described [13].

\section{Results}

\subsection{User Satisfaction and Functionality for Exercises Type}

All five participants acknowledged that the Carter Cuff generally fitted them 
properly but one participant experienced challenge related to the length of the Carter Cuff, one experienced challenge related to the width of the Carter Cuff, two experienced challenge related to the Velcro portion of the Carter Cuff and one participant experienced no challenge with the construction of the Carter Cuff. Three of the five participants required assistance donning the Carter Cuff and none of the participants required assistance doffing the Carter Cuff.

Of the five participants, two participants found donning to be neither difficult nor easy, two participants found donning to be easy and one participant found donning to be very easy. All participants responded that they would wear their Carter Cuff in a public setting and all said they would continue to use the Carter Cuff for weight training. All participants responded that the Carter Cuff allowed them to target all desired muscle groups and, with the exception of one individual, all the exercises could be performed with a full or moderate range of motion, except for the triceps extension. Four of the five participants experienced no difficulty using the Carter Cuff and one individual experienced moderate difficulty.

\subsection{User Experience}

All participants reported using the device in a gym or fitness club setting; in addition, three used the device at home or in a physical therapist's office. Data recorded from the "User Experience" section of the survey (questions 49 to 64) showed that four of the five participants felt as though they experienced some improvement in muscular function after using the Carter Cuff, whereas one did not report any difference or improvement from their use of the device. After a thorough review of the responses, there might be some correlation between frequency of days exercised each week and muscle gain. But is should be emphasized that the participants provided no quantitative evidence to support their perceived changes in muscle gain.

The four participants who experienced physiological changes after using the Carter Cuff also reported a heightened sense of accomplishment, interest to engage in other activities, motivation to exercise, and level of self-esteem. In general, the responses of the participants who reported some weight loss and muscle gain were positive to the motivation and self-efficacy questions.

All respondents reported they used the Carter Cuff on an exercise machine, and other devices-such as kettle bells, barbells, dumbbells, and with a multi-purpose trainer. However, four of the five participants perceived themselves as compensating less with other limbs while performing ADLs after exercising with the Carter Cuff.

\subsection{Effectiveness of Weight Training}

The data in this section emphasized the effectiveness and safety of the Carter Cuff device. Figure 1 elicits the degree of effectiveness per participant. The majority of the participants (4 individuals) agreed that the device was highly effective, and another participant answered that it was somewhat effective. Four of the participants believed that the Carter Cuff was very safe, whereas one felt that 
it was somewhat safe. All individuals reported that the Carter Cuff allowed for proper technique when performing most of the exercises but one individual had difficulty maintaining technique in the chest and overhead press.

\subsection{Open-Ended Questions}

The first question at the end of the survey asked the participants whether the Carter Cuff restricted movement. Only 3 of the 5 participants responded to this question. One participant responded that there were no movement restrictions with the Carter Cuff. Another participant said "The stiffness of the Cuff especially the upper arm at first restricted movement for the first week or so until it got broke in." The third participant said "There was a lot of excess material around the elbow joint that restricted the bend of my elbow. My prosthetist ended up cutting some of it away which helped with the movement, but I still wasn't able to bend my elbow as far as I can without the Carter Cuff on."

Then next question asked the participant if the Carter Cuff promoted the exercise-related movements. The following are some of the notable comments from the five participants:

"The placement of the D-rings allowed a better load leverage and less stress and torque on the prosthetic socket."

"I had no ability to do any exercise related movement prior to the Carter Cuff. It promoted all sorts of movement for me."

"The numerous D-rings allowed me to target exactly where I wanted the force to be applied, allowing me to limit the forces being applied to my prosthesis for each exercise, specifically for deltoid raises and for curls."

"The Cuff did help take weight off my prosthesis socket at certain points in the range of motion for each exercise. The Carter Cuff helped with stability a little bit when using dumbbells and cables."

The next questions asked the participants what they liked about the Carter Cuff. These were some of the notable comments from the five participants:

"It's overall design and the material used to make it. D-rings are in the right places. Very simple to put on and adjust. Easy to remove."

"For me it was a great confidence builder. Having my hands badly injured, it allowed me the freedom to do things in the gym I thought I would never be able to do again."

"Allowed me to lift heavier loads without discomfort. It greatly increased my exercise options and allowed me to do more than I could do with the prosthesis alone."

"I love the look and feel of it. I love that it got me into the gym. I love talking with people in the gym that see me finally working out with weights. The numerous D-rings and their locations are excellent. The design is esthetically pleasing. For lack of a better description it looks quite intense. The cuff is robust; when setup correctly it is quite stable for every exercise. Except for pulling motions with especially heavy loads." 
"The Cuff looked cool and made me feel like a bionic man, haha."

The next question asked the participants what they disliked about the Carter Cuff. Four of the five participants responded to this question. Two of the participants responded that there was nothing they disliked about the Cuff. However, two of the other participants noted limitations:

"While making more motions and exercises available, the Cuff did not meet my most hopeful goal which would be to allow me to lift heavier or for longer since: The design of my prosthesis limited how much weight could be taken over by the cuff. That is, my prosthesis fits tightly around my elbow bones. If the cuff slides down even a little bit when I start lifting heavy weight, almost all of the weight is applied to my socket and not the cuff. It was difficult to strike a balance on the shoulder strap, between taking too much weight in my opposite armpit or not taking any weight."

"Restricted movement, and was a bit of a hassle to use at the gym because I had to modify the gym equipment to suit my needs, which is an added step in getting ready for a set of reps. However, I would recommend the Cuff to someone who is just beginning to try to gain strength on their weaker side. For me, using the Cuff was awkward because I can already do almost every exercise an able bodied person can, but 2 years ago I couldn't, so it would have helped me a lot more if I had started using it when I had very little strength in my amputated arm."

The last open-ended question asked the participants if they would recommend the Carter Cuff to other individuals with upper-extremity disabilities. All five participants responded affirmatively.

\section{Conclusions}

The construction of the Carter Cuff seemed to fit the participants reasonably well, although there were some concerns about the dimensions of the Cuff (length/width) and the Velcro elements of the Cuff. Donning and doffing the Cuff seemed to be of no great concern to the participants although it is likely that depending on the disability, assistance might be required by some. Clearly, for the Cuff to be effective, it must comfortably fit the participant and yet be stable enough not to slip around the participant's residual limb during the exercises. Finally, most of the participants felt that the Carter Cuff allowed them to target the desired muscles during the exercises. We believe it is fair to conclude that user satisfaction among the participants was generally high in terms of the fitting, donning and doffing of the Carter Cuff and the Cuff s capability to target the appropriate muscles during the exercises.

Psychologically, four of the five participants reported a heightened sense of accomplishment, interest to engage in other activities, motivation to exercise, and level of self-esteem (self-efficacy). We believe these results to be of utmost importance as there is evidence in the literature linking these variables, particularly self-efficacy, to exercise adherence [14]. As indicated earlier, individuals 
with disability experience reductions in exercise and physical activity, and it is encouraging that the Carter Cuff could allow these individuals to maintain or improve their level of physical activity. In addition, most of the participants felt that the Carter Cuff was effective in targeting the desired muscles in the various exercises.

Perhaps the most interesting were the participants' responses to the open-ended questions. Based on these responses, it would seem that some design changes to the Carter Cuff may be warranted to insure the maintenance of range of motion and comfort. It would seem desirable for the materials of the Cuff to be as light weight as possible, but strong enough to accommodate the mechanical loads in the various resistance training exercises. The various D-rings were generally viewed as an important element of the Cuff that allowed the participants to attach to the exercise machine in the most effective way. Participants generally liked the "look" of the Carter Cuff.

\section{Future Directions}

Overall, the results of the post-exercise training survey provide preliminary evidence that the Carter Cuff allows people with upper extremity amputation to perform resistance training exercises in a reasonably comfortable and effective manner. However, this evidence is solely based on the qualitative reports from the participants following a six weeks training period. Clearly, a longer training period (minimum of 12 weeks) would be desirable. More quantitative evidence is clearly needed examining changes in muscle girth, motor unit recruitment, muscle strength and endurance. The inclusion of male and females and people of different ethnic/cultural backgrounds should also be done in future studies. In addition, because the Carter Cuff can be used by people with disabilities or injuries that prevent the use of the hand, future testing with people without amputation should also be performed.

\section{Implications of the Research for Occupational Therapy Practice}

Amputations and other disabilities affecting the use of the hand make it difficult or impossible for the patient to participate in resistance training exercises. These types of exercises have been shown to enhance both the physiological and psychological states of the patient:

- The Carter Cuff can potentially offer the occupational therapist another tool to help in the enhancement of upper body strength for people with upper extremity amputation or disability. For these individuals, maintenance and improvement in upper body strength is important to support and control a prosthesis.

- In people with other types of hand injuries or disabilities, the Carter Cuff would allow them to remain physically active, and presumably reduce the time to return to various activities of daily living, recreation and sports. 


\section{Acknowledgements}

We would like to thank Carter Medical Device LLC for providing the Carter

Cuffs used in this study and for helping in the recruitment of participants.

\section{References}

[1] Pepper, M. and Willick, S. (2009) Maximizing Physical Activity in Athletes with Amputations. Current Sports Medicine Reports, 6, 339-344. https://doi.org/10.1249/JSR.0b013e3181c1db12

[2] Webster, J.B., Levy, C.E., Bryant, P.R. and Prusakowski, P.E. (2001) Sports and Recreation for Persons with Limb Deficiency. Archives of Physical Medicine and Rehabilitation, 82, S38-S44. https://doi.org/10.1016/S0003-9993(01)80036-8

[3] Conroy, B.P., Kraemer, W.J., Maresh, C.M. and Dalsky, G.P. (1992) Adaptive Responses of Bone to Physical Activity. Medicine Exercise Nutrition Health, 1, 64-74.

[4] Hurley, B.F., Hagberg, J.M. and Goldberg, A.P. (1988) Resistance Training Can Reduce Coronary Risk Factors without Altering VO2max or Percent Body Fat. Medicine and Science in Sports and Exercise, 20, 150-154. https://doi.org/10.1249/00005768-198820020-00008

[5] Kraemer, W.J. (1994) General Adaptations to Resistance and Endurance Training Programs. In: Baechle, T., Eds., Essentials of Strength Training and Conditioning, Human Kinetics, Champaign, 127-150.

[6] Smutok, M.A., Reece, C. and Kokkinos, P.F. (1993) Aerobic vs. Strength Training for Risk Factor Intervention in Middle-Aged Men at High Risk for Coronary Heart Disease. Metabolism, 42, 177-184. https://doi.org/10.1016/0026-0495(93)90032-J

[7] Stone, M.H., Fleck, S.J., Triplett, N.T. and Kramer, W.J. (1991) Health- and Performance-Related Potential of Resistance Training. Sports Medicine, 11, 210-231. https://doi.org/10.2165/00007256-199111040-00002

[8] Wilmore, J.H. and Costill, D.L. (1994) Physiology of Sport and Exercise. Human Kinetics, Champaign.

[9] Anderson-Hanley, C., Nimon, J.P. and Westen, S.C. (2010) Cognitive Health Benefits of Strengthening Exercise for Community-Dwelling Older Adults. Journal of Clinical and Experimental Neuropsychology, 32, 996-1001. https://doi.org/10.1080/13803391003662702

[10] O'Connor, P.J., Herring, M.P. and Carvalho, A. (2010) Mental Health Benefits of Strength Training in Adults. American Journal of Lifestyle Medicine, 4, 377-396. https://doi.org/10.1177/1559827610368771

[11] American College of Sport Medicine (2011). https://greatist.com/fitness/acsm-releases-new-exercise-guidelines

[12] Bragaru, M., Dekker, R., Geertzen, J.H. and Dijkstra, P.U. (2011) Amputees and Sports. Sports Medicine, 41, 721-740. https://doi.org/10.2165/11590420-000000000-00000

[13] https://www.bodybuilding.com/exercises/finder/?equipmentid=6\&muscleid=1

[14] McAuley, E. and Blissmer, B. (2000) Self-Efficacy Determinants and Consequences of Physical. 


\section{Appendix}

\section{Carter Cuff User Survey}

Dear Participant, Data collected from this confidential survey will be used for research analysis by the Carter Cuff Research Group at San Francisco State University to gain a better understanding of the user requirements for weight training with an assistive device. The survey questions will give you an opportunity to tell us more about your user experience with as well as expectation of a prosthetic and/or assistive device prior to and after using the Carter Cuff for weight training. You may choose to participate or not to participate in this survey. If you do not wish to participate in this survey, you may close the window on the screen of your computer, tablet or other electronic gadget, with no penalty to you. If you choose to participate, you may respond only to the questions that you feel comfortable in answering and may exit anytime within the survey if you choose not to continue with it. Your decision whether or not to participate in this research will have no influence on your present or future status with San Francisco State University. Please answer openly, truthfully and as accurately as you can. The survey should take approximately $20-25$ minutes to complete. Please direct any questions or concerns pertaining to this survey to the principal investigator. Sincerely, Carter Cuff Research Group.

1) What is your gender?
O Male
O Female
O Decline to state

2) What is your age?
O Under 18
O 18 - 25
○ $26-35$
O $36-45$
○ $46-55$
O $56-65$
O $66-75$
O 76 or above

3) What is your height?
O Under 5'0" (under 1.52 meters)
O 5'1" - 5'6" (1.55 - 1.68 meters)
O 5'7" - 5'11" (1.70 - 1.80 meters)
O 6'0" - 6'6" (1.83 - 1.98 meters)
○ $6^{\prime} 77^{\prime \prime}$ or above (2.01 meters or above)

4) What is your weight? 


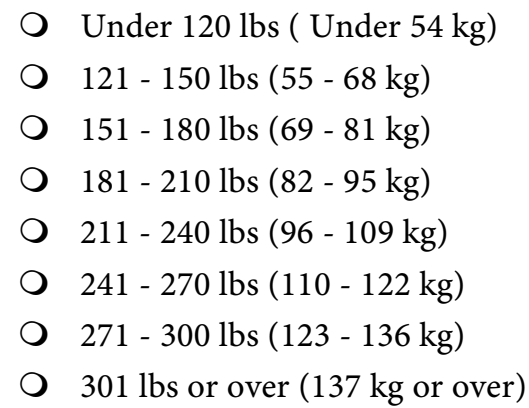

5) What is your ethnicity?
O Asian
O Black/African-American/African-Canadian
O Hispanic/Latino
Spanish
O Native American/Alaska Native/First Nations
O White/Caucasian
Pacific Islander
O Other:
Decline to state

6) Are you a person with an amputation or other upper extremity impairment?

O Amputation

O Upper extremity impairment

If Upper Extremity Impairment Is Selected, Then Skip To What is the extent of your impairment?

7) If you are a person with an amputation, please indicate the affected side(s):
Left
Right

Both

8) Please indicate the level of upper-extremity loss/absence you have. Please check all that apply.

Partial hand amputation. Please specify level of loss or digits lost:
口 Thumb amputation only
$\square$ Wrist disarticulation
$\square$ Transradial
$\square$ Elbow disarticulation
口 Transhumeral
- Shoulder disarticulation
$\square$ Forequarter amputation

9) What is the cause of your amputation(s)? Please check all that apply. 
口 Trauma-related

a Congenital deficiency

a Cancer-related

D Dysvascular

口 Other (please specify)

10) How long has it been since the amputation(s)?

O Less than 1 year

O 1 - 2 years

O 2 - 5 years

O 5 - 10 years

O 10 - 15 years

O 15 - 20 years

O More than 20 years

11) Do you routinely wear a prosthesis?

O Yes

O No

If No Is Selected, Then Skip To Have you had any previous prosthesis experience

12) What is your primary prosthesis?

O Myoelectric prosthesis

O Body-powered prosthesis

O Cosmetic prosthesis

O Other assistive device. Please specify:

13) How many hours per day do you wear your primary prosthesis?

O 1 - 3 hours

O 4 - 6 hours

O 7 - 9 hours

O 10 - 12 hours

O More than 12 hours

14) Did you receive training for using your primary prosthesis?

O Yes

O No

15) How many hours of training did you receive for using your primary prosthesis?

O 1 - 3 hours

O 4 - 6 hours

O 7 - 9 hours

O $10-12$ hours 
More than 12 hours

16) What is your secondary prosthesis?

O Myoelectric prosthesis

Body-powered prosthesis

Cosmetic prosthesis

Other assistive device. Please specify:

O Not applicable

If Not applicable Is Selected, Then Skip To Have you had any previous prosthesis experience, ...

17) How many hours per day do you wear your secondary prosthesis?

O 1 - 3 hours

4 - 6 hours

O 7 - 9 hours

O $10-12$ hours

More than 12 hours

18) Did you receive training for using your secondary prosthesis?

Y Yes

19) How many hours of training did you receive for using your secondary prosthesis?

O 1 - 3 hours

4 - 6 hours

O 7 - 9 hours

O 10 - 12 hours

More than 12 hours

20) Have you had any previous prosthetic or weight training experience with other prosthetic devices? Please check all that apply.

- Myoelectric prosthesis

$\square$ Body-powered prosthesis

$\square$ Cosmetic prosthesis

$\square$ Other assistive device (please specify)

$\square$ No previous training

If No previous training Is Selected, Then Skip To Do you have any weight training experience...

21) Do you currently use a prosthesis for weight training?

○ Yes

O No

If No Is Selected, Then Skip To Do you have any weight training experience...

22) How much weight training experience have you had with a prosthetic device 
other than the Carter Cuff?

O 1 - 3 months

O 3 - 6 months

O 6 - 12 months

O 1 - 5 years

O 5 - 10 years

O 10 - 20 years

O More than 20 years

23) Did you have any weight training experience prior to your amputation?

O None

O 1 - 4 months

O 5 - 8 months

O 9 - 11 months

O 1 - 5 years

O 6 - 10 years

O 11 - 19 years

O 20 years or more

If None Is Selected, Then Skip To Have you had any type of rehabilitation, ... If $1-4$ months Is Selected, Then Skip To Have you had any type of rehabilitation, ... If 5 - 8 months Is Selected, Then Skip To Have you had any type of rehabilitation, ... If 9 - 11 months Is Selected, Then Skip To Have you had any type of rehabilitation, ... If 1 - 5 years Is Selected, Then Skip To Have you had any type of rehabilitation, ... If 6 - 10 years Is Selected, Then Skip To Have you had any type of rehabilitation, ... If $11-19$ years Is Selected, Then Skip To Have you had any type of rehabilitation, ... If 20 years or more Is Selected, Then Skip To Have you had any type of rehabilitation, ...

24) Please indicate the affected side(s) for your upper-extremity impairment.

O Left

O Right

O Both

25) What is the extent of your impairment? Please check all that apply.

- Shoulder and below

- Elbow and below

F Forearm and below

- Wrist and below

- Hand

26) What caused your upper-extremity impairment? Please check all that apply.

口 Trauma-related

a Congenital deficiency

a Age-related 
口 Stroke-related

口 Arthritis

口 Other (please specify)

27) How long have you been impaired?

Less than 1 year

- 1 - 3 years

4 - 6 years

O 7 - 9 years

O 10 - 15 years

O 16 - 19 years

O 20 years or more

28) Have you used any assistive device(s)?

Yes (please specify)

O No

29) Did you have any weight training experience prior to your upper-extremity impairment?

O None

O 1 - 3 months

O 4 - 6 months

O 7 - 11 months

- 1 - 5 years

6 - 10 years

O $11-19$ years

O 20 years or more

30) Have you had any type of therapy for your amputation or impairment?

○ Yes

No

31) What type(s) of therapy? Please check all that apply.

$\square$ Occupational therapy (e.g. rehabilitation for activities of daily living)

$\square$ Physical therapy (e.g. rehabilitation to strengthen weakened muscles)

$\square$ Aquatic therapy (e.g. water rehabilitation to improve strength, flexibility, and mobility)

$\square$ Cognitive therapy (e.g. rehabilitation using mental imagery exercises)

$\square$ Other. Please specify:

32) Did the Carter Cuff fit over your prosthesis or arm properly?

Y Yes

No

33) Did you experience any challenge(s) related to the construction of the Carter Cuff? Please check all that apply. 
$\square$ None

$\square \quad$ Length

$\square$ Width

$\square$ Velcro portions

$\square$ Straps

○ Other. Please specify:

34) Did you require assistance putting on the Carter Cuff?

○ Yes

O No

35) Did you require assistance removing the Carter Cuff?

○ Yes

O No

36) Please rate the ease of donning and doffing the Carter Cuff.

\begin{tabular}{|c|c|c|c|c|c|}
\hline & $\begin{array}{c}\text { Very } \\
\text { Difficult (1) }\end{array}$ & Difficult (2) & $\begin{array}{c}\text { Neither Difficult nor } \\
\text { Easy (3) }\end{array}$ & Easy (4) & Very Easy (5) \\
\hline Donning & O & 0 & 0 & 0 & O \\
\hline Doffing & 0 & 0 & 0 & 0 & 0 \\
\hline
\end{tabular}

37) Would you wear the Carter Cuff in a public setting (e.g. in the gym or weight room)?

O Yes

O No

38) I will continue to use the Carter Cuff for weight training.

Agree

Disagree

39) To what extent did the Carter Cuff allow you to target the desired muscle group? If necessary, consult your healthcare trainer/practitioner.

\begin{tabular}{|c|c|c|c|c|}
\hline & $\begin{array}{c}\text { Targeted None at } \\
\text { All (1) }\end{array}$ & Targeted Some (2) & Targeted All (3) & Not Applicable (4) \\
\hline Lats Pulldown & O & $\mathrm{O}$ & $\mathrm{O}$ & $\mathrm{O}$ \\
\hline Row & O & $\mathrm{O}$ & $\mathrm{O}$ & $\mathrm{O}$ \\
\hline Triceps Extension & $\mathrm{O}$ & $\mathrm{O}$ & $\mathrm{O}$ & $\mathrm{O}$ \\
\hline Chest Press & $\mathrm{O}$ & $\mathrm{O}$ & $\mathrm{O}$ & $\mathrm{O}$ \\
\hline Fly & O & $\mathrm{O}$ & $\mathrm{O}$ & $\mathrm{O}$ \\
\hline Reverse Fly & $\mathrm{O}$ & $\mathrm{O}$ & $\mathrm{O}$ & $\mathrm{O}$ \\
\hline Overhead Press & $\mathrm{O}$ & $\mathrm{O}$ & $\mathrm{O}$ & $\mathrm{O}$ \\
\hline Biceps Curl & $\mathrm{O}$ & $\mathrm{O}$ & $\mathrm{O}$ & $\mathrm{O}$ \\
\hline
\end{tabular}


40) To what extent did the Carter Cuff allow you to perform the following exercises with a full range of motion (ROM)?

\begin{tabular}{|c|c|c|c|c|c|}
\hline & No ROM (1) & $\begin{array}{l}\text { Minimal ROM } \\
\text { (2) }\end{array}$ & $\begin{array}{l}\text { Moderate ROM } \\
\text { (3) }\end{array}$ & Full ROM (4) & $\begin{array}{c}\text { Not Applicable } \\
\text { (5) }\end{array}$ \\
\hline Lats Pulldown & O & O & O & O & O \\
\hline Row & O & O & O & O & O \\
\hline $\begin{array}{l}\text { Triceps } \\
\text { Extension }\end{array}$ & 0 & O & O & O & O \\
\hline Chest Press & O & O & O & 0 & O \\
\hline Fly & O & O & O & O & O \\
\hline Reverse Fly & O & O & O & O & O \\
\hline Overhead Press & O & O & O & O & O \\
\hline Biceps Curl & O & O & O & O & O \\
\hline
\end{tabular}

41) What was your level of difficulty in using the Carter Cuff to perform each of the following exercises?

\begin{tabular}{|c|c|c|c|c|c|}
\hline & $\begin{array}{c}\text { Lots of } \\
\text { Difficulty (1) }\end{array}$ & $\begin{array}{c}\text { Moderate } \\
\text { Difficulty (2) }\end{array}$ & $\begin{array}{l}\text { Slight Difficulty } \\
\text { (3) }\end{array}$ & $\begin{array}{c}\text { No Difficulty } \\
\text { (4) }\end{array}$ & $\begin{array}{c}\text { Not Applicable } \\
\text { (6) }\end{array}$ \\
\hline Lats Pulldown & O & O & O & O & O \\
\hline Row & 0 & 0 & O & 0 & O \\
\hline $\begin{array}{l}\text { Triceps } \\
\text { Extension }\end{array}$ & O & O & O & O & O \\
\hline Chest Press & O & O & $\mathrm{O}$ & O & O \\
\hline Fly & O & O & O & O & O \\
\hline Reverse Fly & O & O & O & $\mathrm{O}$ & O \\
\hline Overhead Press & O & O & O & $\mathrm{O}$ & $\mathrm{O}$ \\
\hline Biceps Curl & 0 & 0 & 0 & 0 & 0 \\
\hline
\end{tabular}

42) What caused the difficulty? Please check all that apply.

a Cuff-related (e.g. design, size, material, weight). Please specify:

- Training equipment-related (e.g. faulty machine, machine limitations)

U User-related (e.g. lack of strength, lack of knowledge of using weight machines or weightlifting, lack of instructions, lack of motivation, lack of confidence)

43) Was the difficulty that you experienced during the use of the Carter Cuff something that you would not experience if you were engaged in weight training without the Carter Cuff?

O Yes

O No 
44) To what extent does the Carter Cuff allow for a wider variety of exercises to be performed?

\begin{tabular}{cccccc}
\hline & Much Less (1) & Slightly Less (2) & No Change (3) & $\begin{array}{c}\text { Slightly More } \\
(4)\end{array}$ & Much More (5) \\
\hline $\begin{array}{c}\text { Variety of } \\
\text { Exercises }\end{array}$ & 0 & 0 & 0 & $\bigcirc$ & $\bigcirc$ \\
\hline
\end{tabular}

45) To what extent has your strength increased after using the Carter Cuff for weight training?

Much Less (1) Slightly Less (2) No Change (3) Slightly More (4) Much More (5)

\begin{tabular}{cllll}
\hline $\begin{array}{c}\text { Change in } \\
\text { Strength }\end{array}$ & $\mathrm{O}$ & $\mathrm{O}$ & $\mathrm{O}$ & $\mathrm{O}$ \\
\hline
\end{tabular}

46) When working out with the Carter Cuff, does it allow for proper lifting technique for each of the following exercises?

\begin{tabular}{|c|c|c|c|}
\hline & No (1) & Yes (2) & Not Applicable (3) \\
\hline Lats Pulldown & O & O & 0 \\
\hline Row & O & O & O \\
\hline Triceps Extension & O & O & O \\
\hline Chest Press & O & O & O \\
\hline Fly & O & O & 0 \\
\hline Reverse Fly & 0 & O & 0 \\
\hline Overhead Press & O & 0 & 0 \\
\hline Biceps Curl & O & O & 0 \\
\hline
\end{tabular}

47) How effective are the D-rings of the Carter Cuff in latching onto the exercise machines and equipment?

\begin{tabular}{|c|c|c|c|c|c|c|}
\hline & $\begin{array}{c}\text { Ineffective } \\
\text { (1) }\end{array}$ & $\begin{array}{c}\text { Somewhat } \\
\text { ineffective (2) }\end{array}$ & $\begin{array}{c}\text { Neither } \\
\text { ineffective or effective } \\
\text { (3) }\end{array}$ & $\begin{array}{l}\text { Somewhat } \\
\text { Effective (4) }\end{array}$ & $\begin{array}{c}\text { Effective } \\
\text { (5) }\end{array}$ & $\begin{array}{c}\text { Very } \\
\text { Effective } \\
(6)\end{array}$ \\
\hline $\begin{array}{c}\text { Degree of } \\
\text { Effectiveness }\end{array}$ & O & O & 0 & 0 & 0 & 0 \\
\hline
\end{tabular}

48) During weight training, do you feel safer using the Carter Cuff than without (e.g. avoidance of injury)?

Very Unsafe (1) Slightly Unsafe (2) Same (3) Slightly Safe (4) Very Safe (5)

$\begin{array}{lllll}\text { Degree of Safety } & 0 & 0 & 0 & 0\end{array}$

49) During the test period, how frequently did you use the Carter Cuff for weight training?

O 5 - 7 days per week

O 4 days per week 
O 3 days per week

O 2 days per week

O 1 day per week

O Less than 1 day per week

50) Where did you conduct your weight training? Please check all that apply.

G Gym or health/fitness club

口 CrossFit box

a Martial arts or MMA studio

a Fighting club

口 Home

Other. Please specify:

51) When you used the Carter Cuff for weight training, were any of the following people also present to assist you? Please check all that apply.

口 Professional or certified personal trainer

D Physical or occupational therapist

Doctor, nurse, or physician's assistant

口 Workout "buddy" or training partner. Please specify:

I used the Carter Cuff without any assistance

52) How often were you accompanied?

Every time I used it

O Most of the time I used it

O Some of the time I used it

53) Did you gain any muscle mass as a result of using the Carter Cuff?

\begin{tabular}{|c|c|c|c|c|c|}
\hline & None (1) & $\begin{array}{c}\text { Small Degree } \\
\text { (2) }\end{array}$ & $\begin{array}{c}\text { Moderate Degree } \\
\text { (3) }\end{array}$ & High Degree (4) & $\begin{array}{l}\text { Very High De- } \\
\text { gree (5) }\end{array}$ \\
\hline Degree of Gain & $\mathrm{O}$ & $\mathrm{O}$ & 0 & O & $\mathrm{O}$ \\
\hline
\end{tabular}

54) Did you lose any weight as a result of using the Carter Cuff?

Y Yes. Please specify a number and indicate pounds or kilograms:

O No

55) What equipment did you use for weight training? Please check all that apply.

Exercise machines

a Barbells

D Dumbbells

a Kettle bells

a Medicine balls 
$\square$ CrossFit structures

$\square$ TRX equipment

$\square$ Other. Please specify:

56) To what extent has using the Carter Cuff given you a sense of accomplishment?

\begin{tabular}{ccccc}
\hline & $\begin{array}{c}\text { No Sense of } \\
\text { Accomplishment } \\
(1)\end{array}$ & $\begin{array}{c}\text { Little Sense of } \\
\text { Accomplishment } \\
(2)\end{array}$ & $\begin{array}{c}\text { Moderate Sense of } \\
\text { Accomplishment } \\
(3)\end{array}$ & $\begin{array}{c}\text { Great Sense of } \\
\text { Accomplishment } \\
(4)\end{array}$ \\
\hline $\begin{array}{c}\text { Sense of } \\
\text { Accomplishment }\end{array}$ & 0 & 0 & 0 & 0 \\
\hline
\end{tabular}

57) To what extent has using the Carter Cuff given you a sense of purpose to engage in other activities on life?

\begin{tabular}{lcccc}
\hline & $\begin{array}{c}\text { No Sense of } \\
\text { Purpose (1) }\end{array}$ & $\begin{array}{c}\text { Little Sense of } \\
\text { Purpose (2) }\end{array}$ & $\begin{array}{c}\text { Moderate Sense of } \\
\text { Purpose (3) }\end{array}$ & $\begin{array}{c}\text { Great Sense of } \\
\text { Purpose (4) }\end{array}$ \\
\hline Sense of Purpose & 0 & $\bigcirc$ & $O$ & $\bigcirc$
\end{tabular}

58) To what extent has using the Carter Cuff affected your motivation to continue to exercise?

No Motivation (1) Little Motivation Moderate Motiva- Great Motivation

(2) $\quad$ tion (3) (4)

Level of motivation $\quad \mathrm{O} \quad \mathrm{O}$

59) What is your level of self-esteem (confidence) since you started using the Carter Cuff?

\begin{tabular}{cccccc}
\hline & $\begin{array}{c}\text { Much Lower } \\
(1)\end{array}$ & $\begin{array}{c}\text { Slightly Lower } \\
(2)\end{array}$ & Same (3) & $\begin{array}{c}\text { Slightly Higher } \\
(4)\end{array}$ & $\begin{array}{c}\text { Much Higher } \\
(5)\end{array}$ \\
\hline $\begin{array}{c}\text { Level of } \\
\text { Self-Esteem }\end{array}$ & 0 & 0 & 0 & 0 & 0 \\
\hline \multicolumn{7}{c}{ Never (1) } & Rarely (2) & Sometimes (3) & $\begin{array}{c}\text { Most of the } \\
\text { Time (4) }\end{array}$ & Always (5) \\
\hline $\begin{array}{c}\text { Transfer of } \\
\text { Confidence }\end{array}$ & 0 & 0 & 0 & $\bigcirc$ & $\bigcirc$ \\
\hline
\end{tabular}

61) Has your outlook in life changed since you started exercising with the Carter Cuff? More positive or more negative?

\begin{tabular}{|c|c|c|c|c|c|}
\hline & $\begin{array}{l}\text { More Negative } \\
\text { (1) }\end{array}$ & $\begin{array}{l}\text { Slightly Negative } \\
\text { (2) }\end{array}$ & Same (3) & $\begin{array}{c}\text { Slightly Positive } \\
\text { (4) }\end{array}$ & $\begin{array}{c}\text { More Positive } \\
\text { (5) }\end{array}$ \\
\hline Outlook in Life & 0 & 0 & O & 0 & O \\
\hline
\end{tabular}

62) As a result of using the Carter Cuff, do you find yourself compensating less with other limbs or body posture during activities of daily living?

\begin{tabular}{cccccc}
\hline & Never (1) & Rarely (2) & Sometimes (3) & Often (4) & $\begin{array}{c}\text { All the Time } \\
\text { (5) }\end{array}$ \\
\hline $\begin{array}{c}\text { Decrease in } \\
\text { Compensation }\end{array}$ & 0 & 0 & 0 & 0 & $\bigcirc$ \\
\hline
\end{tabular}


63) Have you had an improvement in body posture and balance since you started exercising with the Carter Cuff?

\begin{tabular}{llllc}
\hline & None (1) & Some (2) & Much (3) & $\begin{array}{c}\text { An Extreme } \\
\text { Amount (4) }\end{array}$ \\
\hline $\begin{array}{c}\text { Improvement in } \\
\text { overall posture } \\
\text { and balance }\end{array}$ & 0 & 0 & 0 & 0 \\
\hline
\end{tabular}

64) Do you have more control over your prosthetic or assistive device now that you have started exercising with the Carter Cuff?

\begin{tabular}{cccccc}
\hline & Same (1) & Little (2) & Some (3) & A Lot (4) & $\begin{array}{c}\text { Not Applicable } \\
\text { (5) }\end{array}$ \\
\hline $\begin{array}{c}\text { Increase in Control of } \\
\text { Prosthetic/Assistive Device }\end{array}$ & 0 & 0 & 0 & 0 & 0 \\
\hline
\end{tabular}

65) You are about to complete this survey. Your help in providing as much feedback as possible in answering the following questions regarding the Carter Cuff would be greatly appreciated.

66) In what way(s) did the design of the Carter Cuff restrict exercise-related movement?

67) In what way(s) did the design of the Carter Cuff promote exercise-related movement?

68) What did you like about the Carter Cuff?

69) What did you dislike about the Carter Cuff?

70) Do you have any other suggestions or recommendations on improving the design of the Carter Cuff?

71) Would you recommend the use of the Carter Cuff to another upper-extremity amputee or individual with upper-extremity impairment?

O Yes

O No

Thank you for your participation in the Carter Cuff User Survey. Your valuable feedback will definitely be taken into consideration for improving the Carter Cuff. Once you select the NEXT button, your survey responses will be submitted. If you have any questions or suggestions regarding this survey, please contact the principal investigator. 